\title{
The safety of one-per-mil tumescent infiltration into tissue that has survived ischemia
}

\author{
Theddeus Octavianus Hari Prasetyono ${ }^{1,2}$, Eliza Nindita ${ }^{1}$ \\ ${ }^{1}$ Division of Plastic Surgery, Department of Surgery, and ${ }^{2}$ Indonesian Clinical Training and Education Center (ICTEC), Cipto \\ Mangunkusumo Hospital, Faculty of Medicine, Universitas Indonesia, Jakarta, Indonesia
}

Background The aim of this study was to assess the safety of one-per-mil tumescent injections into viable skin flaps that had survived an ischemic insult, in order to assess the potential suitability of one-per-mil tumescent injections in future secondary reconstructive procedures such as flap revision and refinements after replantation.

Methods Forty groin flaps harvested from 20 healthy Wistar rats weighing 220 to $270 \mathrm{~g}$ were subjected to acute ischemia by clamping the pedicle for 15 minutes. All flaps showing total survival on the 7th postoperative day were randomly divided into group $A$ (one-per-mil tumescent infiltration; $n=14$ ), group $B$ (normal saline infiltration; $n=13$ ), and group $C$ (control, with no infiltration; $n=13$ ) before being re-elevated. Transcutaneous oxygen tension $\left(\mathrm{TcPO}_{2}\right)$ was measured before and after infiltration, and changes in $\mathrm{TcPO}_{2}$ were statistically analyzed using analysis of variance, the paired t-test, and the independent t-test. The viability of flaps was also assessed using the Analyzing Digital Images software at 7 days after the second elevation.

Results Thirty-nine flaps survived to the final assessment, with the sole exception of a flap from group $\mathrm{A}$ that did not survive the first elevation. $\mathrm{TcPO}_{2}$ readings showed significant decreases $(P<0.05)$ following both one-per-mil tumescent $(99.9 \pm 5.7 \mathrm{mmHg}$ vs. $37.2 \pm 6.3$ $\mathrm{mmHg})$ and normal saline $(103 \pm 8.5 \mathrm{mmHg}$ vs. $48.7 \pm 5.9 \mathrm{mmHg})$ infiltration. Moreover, all groin flaps survived with no signs of tissue necrosis.

Conclusions One-per-mil tumescent infiltration into groin flap tissue that had survived ischemia did not result in tissue necrosis, although the flaps experienced a significant decrease of cutaneous oxygenation.

Keywords Epinephrine / Hand injuries / Ischemia / Reperfusion injury / Vasoconstriction

Received: 11 Mar 2018 • Revised: 18 Nov 2018 • Accepted: 8 Jan 2019

pISSN: 2234-6163 • elSSN: 2234-6171 • https://doi.org/10.5999/aps.2018.00248 • Arch Plast Surg 2019;46:108-113

\author{
Correspondence: \\ Theddeus Octavianus Hari Prasetyono \\ Division of Plastic Surgery, \\ Department of Surgery, Cipto \\ Mangunkusumo Hospital, Faculty of \\ Medicine, Universitas Indonesia, J. \\ Diponegoro No. 71, Jakarta 10430, \\ Indonesia \\ Tel: +62-21-3146938 \\ Fax: $+62-21-31931424$ \\ E-mail: teddyohprasetyono@yahoo.com
}

The author thanks Dr. Fransisca for providing assistance with manuscript preparation.

\section{INTRODUCTION}

Although tissue tolerance to ischemia is highly variable, ischemia may progress quickly to tissue necrosis unless an immediate intervention is performed to remedy the situation. Ischemia- induced complications following flap reconstruction can lead to functional and cosmetic morbidities due to additional or repeated operations [1-3]. In free flaps alone, ischemic necrosis, either partial or total, still occurs in $5 \%$ to $10 \%$ of cases, even when performed by an experienced operator [1,2]. Furthermore, in 
hand surgery, full formal repair of all structures sometimes may not be possible during replantation and complex hand injuries due to the duration of ischemia and the nature of the injury. Hence, patients undergoing replantation have demonstrated increased rates of secondary surgical revisions [4-6].

Interestingly, the timing of secondary procedures does not differ tremendously between cases of traumatic injuries and replantation. No fixed period has been universally accepted in terms of secondary procedures. Instead, the prime determinant of timing is the status of the soft tissue or skin cover at the proposed surgery site, including subsidence of edema, infection, induration, and delayed wound healing as a result of ischemia $[4,6,7]$. Generally, secondary procedures should not be considered until survival of the replanted finger can be guaranteed [6]. In the non-tourniquet technique of hand surgery, one needs to infiltrate tumescent solution into tissues that already have survived an ischemic injury, both as local anesthesia and to create a bloodless surgical field. The benefits and safety of the tumescent technique using epinephrine-containing local anesthesia have been documented [8-10]. Through retrospective studies, the use of a very diluted concentration of epinephrine (i.e., the oneper-mil tumescent technique) has also been confirmed as effective and safe for a wide range of indications and several different procedures $[9,11,12]$. With reference to the recommended timing of secondary surgery, which is determined based on tissue status, the authors posed the question of whether it is safe to apply the tumescent technique to facilitate such procedures.

\section{METHODS}

This study was conducted to assess the safety of infiltrating oneper-mil tumescent solution into tissue that has already survived ischemic conditions. A randomized experimental study was conducted in 20 Wistar rats ( 12 males and 8 females, weighing $220-270 \mathrm{~g}$ ) at the Animal Laboratory, Faculty of Medicine, Universitas Indonesia. Randomization by simple random sampling was conducted regarding the use of the right and left sides of the groin. All rats were housed with a 12-hour light/dark schedule and received stock diet and water ad libitum for 7 days before surgery. Approval was obtained from the Ethics Committee of Faculty of Medicine, Universitas Indonesia (No. 258/ UN2.F1/ETIK/2016) before conducting this study.

Anesthesia was provided by intramuscular injection of $35 \mathrm{mg} / \mathrm{kg}$ of ketamine and $5 \mathrm{mg} / \mathrm{kg}$ of xylazine. Bilateral groin flaps, each sized $3 \times 2 \mathrm{~cm}$, were designed with a projection of the superficial inferior epigastric artery on their surface. Each groin flap was subjected to an ischemic state by clamping the pedicle of the vessel for 15 minutes before the flaps were sutured back into

\section{Fig. 1. Pedicle clamping}

The vessels were clamped for 15 minutes to simulate ischemia.

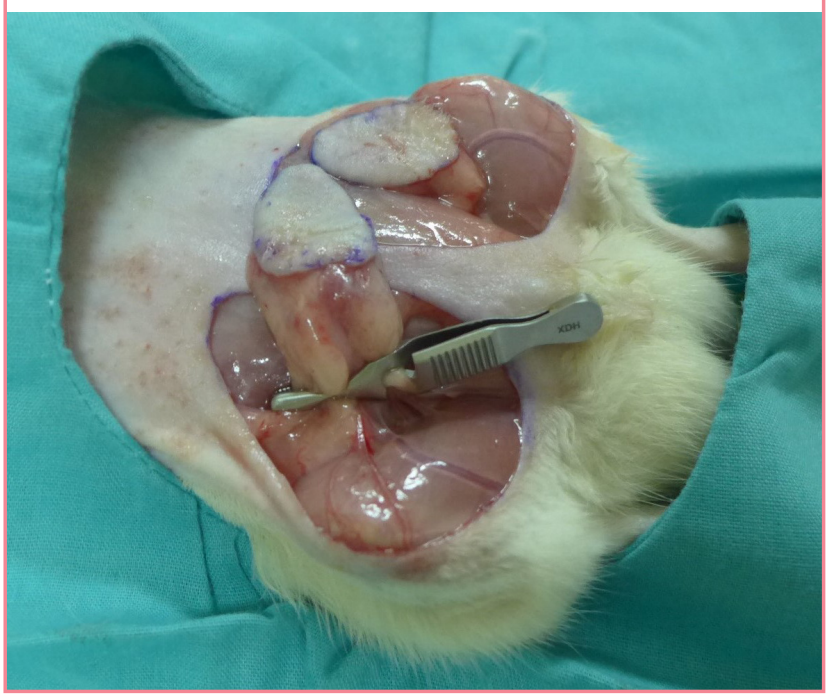

place (Fig. 1).

The area of flap survival was then evaluated and assessed clinically on day 7 after surgery through photographs was taken with a Leica D-Lux Type 109 digital camera (Leica, Wetzlar, Germany). The photos were captured frontally, from a $30-\mathrm{cm}$ distance, in automatic mode. The photos were then analyzed with the Analyzing Digital Image software (Lawrence Hall of Science, Berkeley, CA, USA) to calculate the percentage of necrotic area. Flaps that experienced either partial or total necrosis were excluded. Only flaps that totally survived (100\% of its dimensions) underwent the second surgical procedure, for which they were randomly assigned to three groups.

Flaps in group A were gently infiltrated subcutaneously with 3 $\mathrm{mL}$ of one-per-mil tumescent solution using a $1-\mathrm{mL}$ syringe and a 26-gauge needle at 10 minutes before elevation. The one-permil tumescent solution was a mixture of 1:1,000,000 epinephrine in normal saline. The same injection technique was used in group $\mathrm{B}$, but with $3 \mathrm{~mL}$ of normal saline. Group $\mathrm{C}$ served as the control group, in which the flap was harvested without any injection in advance. Likewise, as in the first surgical procedure, the flap was immediately sutured back to the donor site with 5-0 silk sutures, while the animals were kept alive for further observation. All flaps in groups A and B were measured with a TCM CombiM module version 903-111 (Radiometer Medical ApS, Copenhagen, Denmark) to quantify the oxygen tension level $\left(\mathrm{TcPO}_{2}\right)$. The sensor used was the tc Sensor 84 version 945-737 (Radiometer Basel AG, Copenhagen, Denmark). The same test was applied to all flaps in group $\mathrm{C}$ pre-surgically.

Seven days after the second surgical procedure, the viability of the flaps was re-assessed, using the same technique that was de- 
scribed earlier for the assessment at day 7 after the first surgical procedure.

Using SPSS Statistics version 20.0 for Mac (IBM Corp., Armonk, NY, USA), the data were analyzed using the paired t-test, analysis of variance, and the unpaired t-test. Homogeneity was tested with the Shapiro-Wilk test.

\section{RESULTS}

The mean weight of the rats was $232 \pm 17.7 \mathrm{~g}$. Only one flap was excluded due to total necrosis following the first surgical procedure. Thus, the study proceeded with 39 flaps, which were equally distributed among all groups. An analysis of flap survival before and after the second surgical procedure is presented in Fig. 2. As can be seen, the flap area did not differ across the groups. Furthermore, no flap showed a significant change in area before and after the second surgical procedure. The mean flap areas for groups A, B, and C were $5.11 \pm 0.13,4.96 \pm 0.12$, and $4.94 \pm 0.15 \mathrm{~cm}^{2}$, respectively.

The mean $\mathrm{TcPO}_{2}$ at 7 days after the first surgical procedure was $99.9 \pm 5.7,103 \pm 8.5$, and $102 \pm 5.3 \mathrm{mmHg}$ in groups A, B, and $\mathrm{C}$, respectively. Following one-per-mil tumescent and normal saline infiltration, the $\mathrm{TcPO}_{2}$ readings (group A, 37.2 \pm 6.3 $\mathrm{mmHg}$; group $\mathrm{B}, 48.7 \pm 5.9 \mathrm{mmHg}$ ) decreased significantly $(\mathrm{P}<0.05)$ compared to the pre-injection state (Table 1$)$.

During surgery, the adjunctive use of epinephrine in the one-

\section{Fig. 2. Flap survival area analysis}

The surviving flap area was analyzed using the Analyzing Digital Images software. Images were taken immediately after the second surgical procedure (A) and at postoperative day 7 (B).
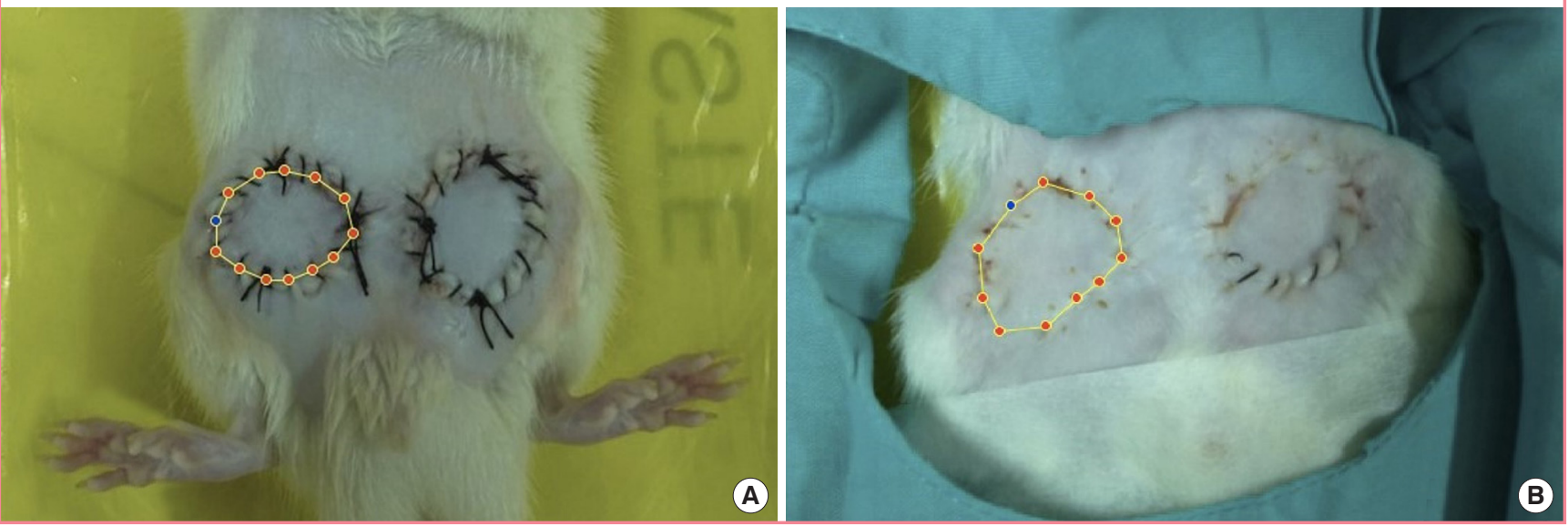

Table 1. Transcutaneous oxygen tension $\left(\mathrm{TcPO}_{2}\right)$ values of all flap samples

\begin{tabular}{|c|c|c|c|c|c|}
\hline \multirow{2}{*}{ Sample No. } & \multicolumn{2}{|c|}{ Group A (tumescent) } & \multicolumn{2}{|c|}{ Group B (normal saline) } & \multirow{2}{*}{$\begin{array}{c}\text { Group C } \\
\text { Without injection }\end{array}$} \\
\hline & Pre-injection & Post-injection & Pre-injection & Post-injection & \\
\hline 1 & 101 & 46 & 97 & 53 & 96 \\
\hline 2 & 99 & 45 & 95 & 48 & 108 \\
\hline 3 & 93 & 43 & 106 & 51 & 99 \\
\hline 4 & 104 & 32 & 115 & 54 & 101 \\
\hline 5 & 96 & 30 & 94 & 47 & 106 \\
\hline 6 & 102 & 38 & 90 & 56 & 96 \\
\hline 7 & 99 & 46 & 115 & 42 & 98 \\
\hline 8 & 91 & 38 & 109 & 48 & 102 \\
\hline 9 & 106 & 31 & 103 & 41 & 109 \\
\hline 10 & 103 & 39 & 95 & 54 & 97 \\
\hline 11 & 94 & 29 & 104 & 38 & 99 \\
\hline 12 & 99 & 31 & 114 & 45 & 112 \\
\hline 13 & 112 & 36 & 102 & 56 & 104 \\
\hline Mean \pm SD & $99.9 \pm 5.7$ & $37.2 \pm 6.3$ & $103 \pm 8.5$ & $48.7 \pm 5.9$ & $102 \pm 5.3$ \\
\hline
\end{tabular}




\section{Fig. 3. Flap appearance after tumescent injection}

Elevation of a groin flap showing the hemostatic effects of the one-per-mil tumescent injection (left). The flap appeared much paler than those in group $\mathrm{B}$ or $\mathrm{C}$ (right).

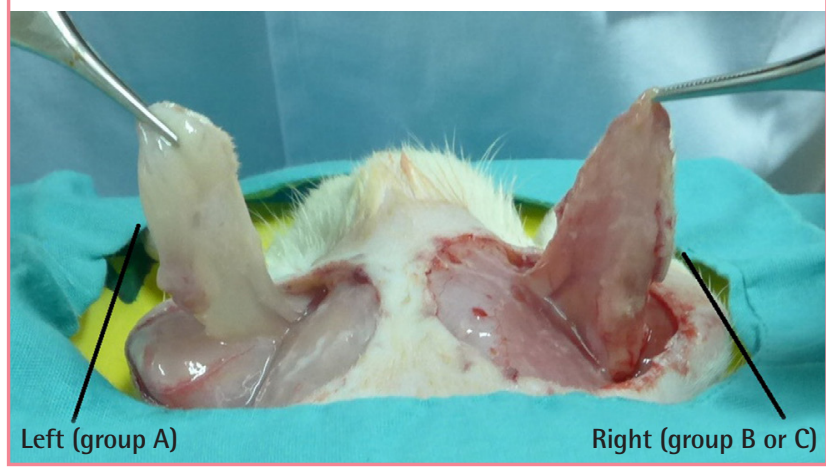

per-mil tumescent (group A) showed a clear hemostatic effect, as depicted in Fig. 3. The flaps in group A appeared much paler than those in groups B and C.

\section{DISCUSSION}

The benefits of local infiltration with a solution containing epinephrine in the field of reconstructive surgery for the facial region and beyond have been established for many decades. The benefits of the tumescent technique are especially convincing for liposuction, as a way of administering a greater dose of lidocaine, reaching as high as $45 \mathrm{mg} / \mathrm{kg}$ [13]. The tumescent technique is also well accepted for its safety when applied properly in the finger, hand, and upper extremity, especially regarding its vasoconstrictive effects $[11,12]$.

Concerns about the possible deleterious effects of epinephrine-containing local anesthesia could be addressed by confirming its safety in tissue that has survived previous ischemic insults. The outcomes of this experimental study are promising for the future, as all flaps survived after being infiltrated with epinephrine-containing solution using the tumescent technique. It was also proven that every flap successfully maintained its dimensions without any size reduction caused by small partial necrotic areas within, the presence or absence of which was not specifically determined.

The first $\mathrm{TcPO}_{2}$ measurements of the flaps, made a week after the first surgical procedure in which the flaps suffered an ischemic insult, showed no significant differences across all groups. All flaps had $\mathrm{TcPO}_{2}$ values exceeding $60 \mathrm{mmHg}$ (Table 1), which are associated with good perfusion. These values were compatible with the clinical assessment that all the flaps were eligible to undergo the second surgical procedure.

It might be debatable whether the clamping time ( 15 minutes) was sufficient to create ischemia, as no standard clamping time exists. Small animal skin flaps that undergo arterial clamping may be undetectable by oxygen saturation measurements after only 20 seconds [14]. Another animal study showed that changes in tissue oxygen saturation were time-dependent, with oxygen saturation in both arteries and veins dropping to its lowest level after 15 minutes and plateauing for the next 15 minutes [15]. A clinical study in humans even used 4-minute vessel occlusions to delineate the pattern of reperfusion [16]. Regardless, the main idea of the current study was to represent the actual circumstances of free flaps and revascularization. In real clinical settings, free flaps are transferred with the shortest ischemic time possible. The same concept is applied for revascularization.

The 1:1,000,000 epinephrine caused a significant decrease of the skin perfusion in the flaps; the mean $\mathrm{TcPO}_{2}$ was $37.2 \pm 6.3$ $\mathrm{mmHg}$, almost half of $60 \mathrm{mmHg}$. All flaps in group A showed a marked difference in tissue color, as shown in Fig. 3, wherein the flaps look pale. Nonetheless, the $\mathrm{TcPO}_{2}$ of all flaps but one was still greater than $30 \mathrm{mmHg}$ (one flap had a reading of 29 $\mathrm{mmHg}$ ), which could be normatively associated with partial or complete survival [17]. In fact, no flap suffered from any necrosis whatsoever.

Interestingly, the mean $\mathrm{TcPO}_{2}$ level of group $\mathrm{B}(48.7 \pm 5.9 \mathrm{mmHg})$ also decreased significantly from the baseline $(103 \pm 8.5 \mathrm{mmHg}$; $\mathrm{P}<0.05$ ) (Table 1). The fact shows that a 1:1,000,000 concentration of epinephrine caused a significant decrease of tissue perfusion through its role as an $\alpha / \beta$-adrenergic vasoconstrictor $[5,12]$. When compared to the relatively small tissue volume, the massive amount of solution injected into the tissue plays an important role in causing hydrostatic vasocompression $[5,12$, 18]. Although further research is needed to explain the exact mechanism through which the oxygen perfusion level is reduced, this study indicates that epinephrine is a potential contributing factor.

In assessing flap perfusion, $\mathrm{TcPO}_{2}$ levels were measured as an adjunct to clinical observation that allowed an immediate evaluation of ischemia. Epinephrine has been demonstrated to cause effective vasoconstriction even at concentrations as low as 1 : $1,000,000[5,12]$. In normal saline infiltration, the excessive accumulation of isotonic fluid through interstitial subcutaneous infiltration can predispose to hemodilution and produce edema, which in turn reduces the vascular transmural pressure gradient and physically compresses capillaries, thereby reducing nutritive tissue perfusion $[19,20]$. Therefore, the $\mathrm{TcPO}_{2}$ values decreased to a lesser extent after infiltration in the normal saline group than in the one-per-mil tumescent group, since both mechanical compression and the action of epinephrine contributed to the effect. However, the $\mathrm{TcPO}_{2}$ readings in both groups after infil- 
tration were within the range of values associated with partial or complete survival.

In general, the results demonstrate that one-per-mil tumescent infiltration into viable groin flap tissue did not have deleterious effects on flap perfusion. This study confirms that the vasoconstrictive effect of 1,000,000 epinephrine in the tumescent infiltration technique does not completely restrict blood perfusion, even in flap tissue that has previously suffered from an ischemic condition. Regarding precautions that must be taken in applying tumescent local anesthesia, it must be stressed that the oneper-mil tumescent application in this study was only performed on groin flaps that showed total clinical survival. It is not advisable to infiltrate tissue that shows problems with viability.

Based on our results for the tissue response to one-per-mil tumescent application in viable flaps, we can assume that one-permil tumescent solution is unlikely to cause any harm to flaps as long as the perfusion of the flap is established. Thus, it may be possible to consider one-per-mil tumescent application in future secondary procedures, such as flap revision and refinement surgery after replantation.

In summary, infiltration of one-per-mil tumescent solution into viable groin flaps did not yield any clinical signs of flap failure, even though the flaps had previously suffered from an ischemic condition. Although flap failure is the most feared complication when employing the tumescent technique due to the adjunctive action of epinephrine, this study showed that the epinephrine in the one-per-mil tumescent solution can be considered safe and beneficial as an adjunctive agent when used properly.

\section{NOTES}

\section{Conflict of interest}

No potential conflict of interest relevant to this article was reported.

\section{Ethical approval}

The study was approved by the The Ethics Committee of Faculty of Medicine, Universitas Indonesia (No. 258/UN2.F1/ ETIK/2016).

\section{Author contribution}

Concept and design of the study, performing the analysis and data interpretation, and approving the final manuscript: Prasetyono TO. Conducting the acquisition and analysis of the data and drafting the article to present important results: Nindita $\mathrm{E}$.

\section{ORCID}

Theddeus Octavianus Hari Prasetyono https://orcid.org/00000003-3675-4309

Eliza Nindita http://orcid.org/0000-0001-6428-3159

\section{REFERENCES}

1. Sabapathy SR, Bhardwaj P. Secondary procedures in replantation. Semin Plast Surg 2013;27:198-204.

2. Larson JV, Kung TA, Cederna PS, et al. Clinical factors associated with replantation after traumatic major upper extremity amputation. Plast Reconstr Surg 2013;132:911-9.

3. Flint P, Cummings C, Haughey B, et al. Cummings otolaryngology head \& neck surgery. Philadelphia: Mosby Elsevier; 2010.

4. Hui-Chou HG, Sulek J, Bluebond-Langner R, et al. Secondary refinements of free perforator flaps for lower extremity reconstruction. Plast Reconstr Surg 2011;127:248-57.

5. Lalonde D, Martin A. Epinephrine in local anesthesia in finger and hand surgery: the case for wide-awake anesthesia. J Am Acad Orthop Surg 2013;21:443-7.

6. Al Youha S, Lalonde DH. Update/review: changing of use of local anesthesia in the hand. Plast Reconstr Surg Glob Open 2014;2:e150.

7. Bueno RA Jr, Battiston B, Ciclamini D, et al. Replantation: current concepts and outcomes. Clin Plast Surg 2014;41: 385-95.

8. Pederson WC, Sherman R. Reconstructive surgery of the mutilated hand. In: Chang J, Neligan P, editors. Plastic Surgery. 3rd ed, vol. 6. New York: Elsevier Inc.; 2013. p. 250-81.

9. Klein JA. Tumescent technique for local anesthesia improves safety in large-volume liposuction. Plast Reconstr Surg 1993;92:1085-98.

10. Hanke C, Sommer B, Sattler G, et al. Tumescent local anesthesia. Darmstadt: Springer-Veriag Berlin Heidelberg; 2001.

11. Lalonde D, Martin A. Tumescent local anesthesia for hand surgery: improved results, cost effectiveness, and wideawake patient satisfaction. Arch Plast Surg 2014;41:312-6.

12. Prasetyono TO, Biben JA. One-per-mil tumescent technique for upper extremity surgeries: broadening the indication. J Hand Surg Am 2014;39:3-12.

13. Klein JA, Jeske DR. Estimated maximal safe dosages of tumescent lidocaine. Anesth Analg 2016;122:1350-9.

14. Prasetyono TO, Adianto S. The relationship between oxygen saturation and color alteration of a compromised skin flap: experimental study on the rabbit. Arch Plast Surg 2013; 40:505-9.

15. Kagaya Y, Ohura N, Kurita M, et al. Examination of tissue 
oxygen saturation (StO2) changes associated with vascular pedicle occlusion in a rat Island flap model using near-Infrared spectroscopy. Microsurgery 2015;35:393-8.

16. Adingupu DD, Thorn CE, Casanova F, et al. Blood oxygen saturation after ischemia is altered with abnormal microvascular reperfusion. Microcirculation 2015;22:294-305.

17. Thornton JF, Gosman AA. Skin grafts and skin subtitutes and principles of flaps. Dallas: Selected Readings in Plastic
Surgery; 2004.

18. Ollague JE, Zabielinski M, Nouri K. Anesthesia in dermatologic surgery. In: Nouri K, editior. Dermatologic surgery: step by step. Chichester: Wiley-Blackwell; 2012. p. 20-4.

19. Venkataram J. Tumescent liposuction: a review. J Cutan Aesthet Surg 2008;1:49-57.

20. Taylor AE, Moore TM. Capillary fluid exchange. Am J Physiol 1999;277(6 Pt 2):S203-10. 